Water constraints on European power supply under climate change: impacts on electricity prices

This content has been downloaded from IOPscience. Please scroll down to see the full text. 2013 Environ. Res. Lett. 8035010

(http://iopscience.iop.org/1748-9326/8/3/035010)

View the table of contents for this issue, or go to the journal homepage for more

Download details:

IP Address: 147.125.65.186

This content was downloaded on 29/02/2016 at 09:12

Please note that terms and conditions apply. 


\title{
Water constraints on European power supply under climate change: impacts on electricity prices
}

\author{
Michelle T H van Vliet ${ }^{1,2}$, Stefan Vögele $^{3}$ and Dirk Rübbelke ${ }^{4,5}$ \\ ${ }^{1}$ Earth System Science-Climate Change and Adaptive Land and Water Management, Wageningen \\ University and Research Centre, PO Box 47, 6700 AA Wageningen, The Netherlands \\ ${ }^{2}$ International Institute for Applied Systems Analysis, Schlossplatz 1, A-2361 Laxenburg, Austria \\ ${ }^{3}$ Forschungszentrum Jülich, Institute of Energy and Climate Research-System Analyses and \\ Technology Evaluation, D-52425 Jülich, Germany \\ ${ }^{4}$ Basque Centre for Climate Change, Alameda Urquijo, 4-4, E-48008 Bilbao, Spain \\ ${ }^{5}$ IKERBASQUE, Basque Foundation for Science, E-48011, Bilbao, Spain \\ E-mail: michelle.vanvliet@wur.nl, s.voegele@fz-juelich.de and dirk.ruebbelke@bc3research.org
}

Received 18 March 2013

Accepted for publication 31 May 2013

Published 3 July 2013

Online at stacks.iop.org/ERL/8/035010

\begin{abstract}
Recent warm, dry summers showed the vulnerability of the European power sector to low water availability and high river temperatures. Climate change is likely to impact electricity supply, in terms of both water availability for hydropower generation and cooling water usage for thermoelectric power production. Here, we show the impacts of climate change and changes in water availability and water temperature on European electricity production and prices. Using simulations of daily river flows and water temperatures under future climate (2031-2060) in power production models, we show declines in both thermoelectric and hydropower generating potential for most parts of Europe, except for the most northern countries. Based on changes in power production potentials, we assess the cost-optimal use of power plants for each European country by taking electricity import and export constraints into account. Higher wholesale prices are projected on a mean annual basis for most European countries (except for Sweden and Norway), with strongest increases for Slovenia (12-15\%), Bulgaria (21-23\%) and Romania (31-32\% for 2031-2060), where limitations in water availability mainly affect power plants with low production costs. Considering the long design life of power plant infrastructures, short-term adaptation strategies are highly recommended to prevent undesired distributional and allocative effects.
\end{abstract}

Keywords: power generation, electricity prices, water resources, water temperature, climate change, energy security

S] Online supplementary data available from stacks.iop.org/ERL/8/035010/mmedia

\section{Introduction}

Hydropower and thermoelectric (nuclear and fossil-fuelled) power plants currently contribute to more than $91 \%$ of total

Content from this work may be used under the terms of the Creative Commons Attribution 3.0 licence. Any further distribution of this work must maintain attribution to the author(s) and the title of the work, journal citation and DOI. electricity production in Europe. At present, $74 \%$ of total electricity supply is generated by thermoelectric power plants and $17 \%$ by hydropower plants (EIA, accessed 2013 for year 2010). The European energy sector therefore strongly depends on the availability of water resources for hydropower generation, and also on the temperatures of water for cooling of thermoelectric power plants. In particular coal-fired and nuclear power plants rely on large volumes of water for cooling. The thermoelectric power sector is compared to other 


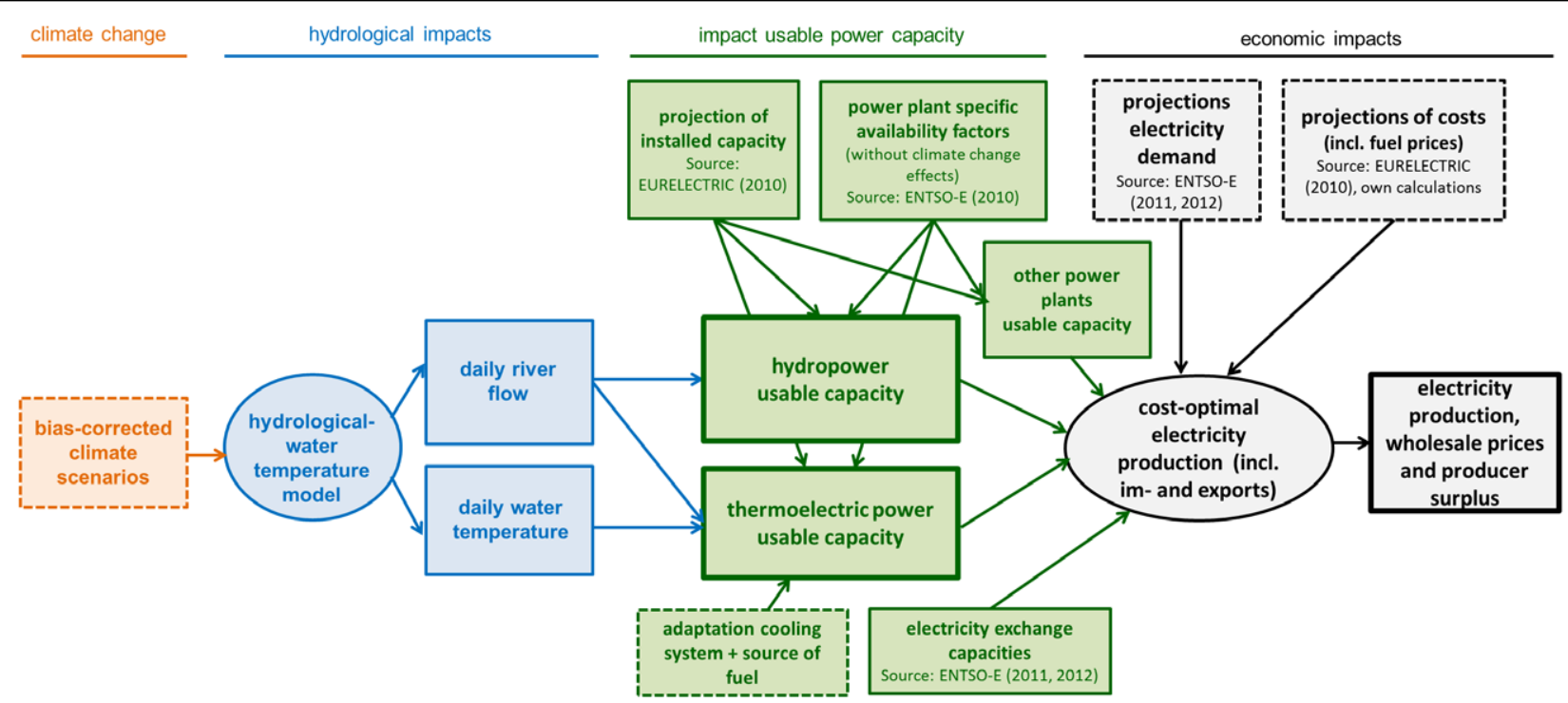

Figure 1. Schematic representation of methodological framework.

sectors (e.g. agriculture, industry, domestic use) the largest water user in Europe, accounting for about $43 \%$ of total surface water withdrawal (EUREAU 2009).

Recent warm, dry summers (e.g. 2003, 2006 and 2009) showed the vulnerability of the European power sector to reduced water availability and high river temperatures. Several thermoelectric power plants were forced to reduce production, because of environmental restrictions on cooling water use, as water availability was low and legal temperature limits were exceeded (Förster and Lilliestam 2010). In particular nuclear power plants were vulnerable to cooling water shortages during recent warm, dry summers. Figure S1 (supplementary information available at stacks.iop.org/ ERL/8/035010/mmedia) shows that both nuclear power plants with once-through and recirculation (tower) cooling systems were affected. Hydropower generation was also reduced during prolonged droughts with low water levels, e.g. the droughts of 2002 and 2003 in Scandinavia (Kuusisto 2004). This had distinct economic impacts like increased electricity prices in northern European countries with high hydropower consumption (Kuusisto 2004, Schmidt-Thomé and Kallio 2006). Limited supply of thermoelectric power and increased production costs also increased electricity prices in other parts of Europe during dry, warm summer periods (Boogert and Dupont 2005, McDermott and Nilsen 2011).

Due to climate change, periods with low summer river flows in combination with high water temperatures are expected to occur more frequently in Europe (Van Vliet et al 2013). This is likely to increase environmental restrictions on cooling water use with substantial reductions in power plant capacities for the next 20-50 years in case adaptation measures are not taken (Van Vliet et al 2012b).

Other previous studies showed performance losses of thermoelectric power plants under climate change (Hoffmann et al 2013, Linnerud et al 2011). Hydropower generating capacity will also be affected by altered river flow patterns under climate change (EEA 2012, Lehner et al
2005). Hydropower is currently the main renewable energy source contributing to electricity supply in Europe, and its contribution is anticipated to rise significantly in the next decades (e.g. GEA 2012, Punys et al 2008). It is therefore also important to include the future power plant stock in calculations of changes in hydropower and thermoelectric power generating capacity (Rübbelke and Vögele 2013), and future changes in water demands for electricity generation (Davies et al 2013, Flörke et al 2012, 2011, Kyle et al 2013).

Changes in thermoelectric and hydropower capacity can have important economic consequences, like changes in electricity prices (Mideksa and Kallbekken 2010) and altered import and export balances between different countries (Kopytko and Perkins 2011). This has also previously been demonstrated by Rübbelke and Vögele (2011, 2013) who focused mainly on climate change impacts on nuclear power plants using scenarios that assume slight and more serious water scarcity in Europe.

Here, we assess the impacts of climate change on European electricity production and prices with a focus on both thermoelectric (nuclear and fossil-fuelled) power and hydropower, and using hydrological and water temperature modelling results for future climate. We used simulations of daily river flow and water temperature projections that were produced using a physically based hydrological-water temperature modelling framework with climate model data for 2031-2060 (Van Vliet et al 2012b). These projections of river flows and water temperatures were used in a thermoelectric power and hydropower production model to calculate impacts on power generating capacity. In addition, we explored the effectiveness of adaptation strategies regarding replacements in cooling systems and changes in source of fuels of thermoelectric power plants. Based on the changes in potential electricity generation, we modelled the cost-optimal use of power plants for each European country by including future power plants stocks and taking electricity import and export constraints into account. 


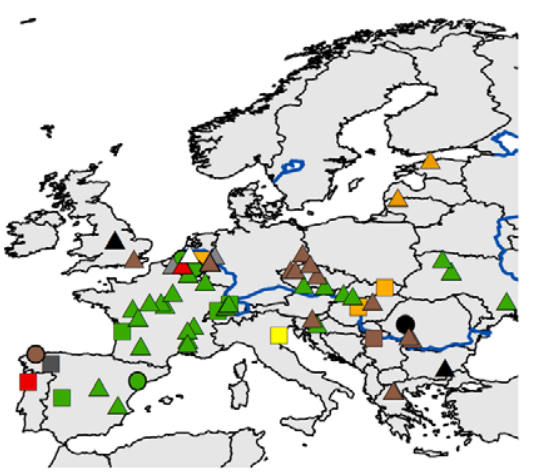

\begin{tabular}{ll}
$\begin{array}{l}\text { once-through cooling } \\
\text { Coal/Oil }\end{array}$ & \\
$\square \quad$ Gas & $\begin{array}{l}\text { recirculation (tower) } \\
\text { cooling }\end{array}$ \\
$\square \quad$ Gas/Oil & $\boldsymbol{\Delta}$ Coal \\
$\square \quad$ Lignite & $\Delta$ Coal/Gas/Oil \\
$\square \quad$ Nuclear & $\Delta$ Coal/Oil \\
$\square \quad$ Oil & $\Delta$ Gas \\
combination cooling & $\Delta$ Gas/Oil \\
$-\quad$ Coal & $\Delta$ Lignite \\
$0 \quad$ Lignite/Coal & $\Delta \quad$ Nuclear \\
\hline$\quad$ Nuclear &
\end{tabular}

Figure 2. Location of power plants, cooling system type (symbols) and source of fuel (colours).

\section{Models and scenarios}

The methodological framework of this study is summarized in figure 1 . We used daily river flow and water temperature simulations for Europe under current and future climate, which were produced with a physically based hydrologicalwater temperature modelling framework (Van Vliet et al 2012b). This modelling framework consists of the Variable Infiltration Capacity (VIC) model (Liang et al 1994) and one-dimensional stream temperature River Basin Model (RBM) (Yearsley 2009, 2012). The modelling framework was applied on a daily time step and $0.5^{\circ} \times 0.5^{\circ}$ spatial resolution. The geographic extent is defined to include the European continent excluding the northern islands and Ural region. The performance of the modelling framework was previously evaluated for Europe using observed daily river flow and water temperature series for river basins with different characteristics (climate zones, human impacts). This showed an overall realistic representation of the observed conditions for 1971-2000 (Van Vliet et al 2012a, 2012b). Daily simulations of river flow and water temperature were produced for the period 1971-2000 (reference) and for 2031-2060 by forcing the hydrological and water temperature modelling framework with biased-corrected general circulation model (GCM) output (Hagemann et al 2011) for both the IPCC SRES A2 (medium-high) and B1 (low) emission scenarios (Nakicenovic et al 2000) (see supplementary section 1 for details, available at stacks.iop. org/ERL/8/035010/mmedia).

In a next step, we quantified the impacts of changes in river flow and water temperature under climate change on thermoelectric and hydropower generating capacity in Europe. Climate change impacts on hydropower capacity were assessed by calculating gross hydropower potentials according to a similar approach as previously tested by Lehner et al (2005). In this approach, gross hydropower potential is directly calculated from gridded datasets of water availability and elevation differences, without requiring additional data of exact location and installed capacities of hydropower plants (see supplementary section 2 for equation and details, available at stacks.iop.org/ERL/8/035010/mmedia). Lehner et al (2005) concluded that this approach (with use of local elevation differences) can be a good indicator for estimating the relative change in actual hydropower potential. We used gridded simulations of daily river flow under both reference (1971-2000) and future (2031-2060) climate for the SRES A2 (medium-high) and B1 (low) emissions scenario to quantify impacts on gross hydropower potential. Country based changes were subsequently estimated by calculating the mean change in gross hydropower potential for all grid cells within each country.

Impacts on thermoelectric power capacity were quantified with a thermoelectric power production model (Koch and Vögele 2009, Rübbelke and Vögele 2011). This model calculates in a first step the water demands of power plants based on their efficiency, installed capacity, cooling system type and the maximum allowed water temperature (increase). In a next step, the useable power plant capacity is calculated based on the estimated daily required water demand, environmental limitations (maximum water temperature (increase) and water withdrawal) and the daily simulations of river flow and water temperature at the power plant site under reference (1971-2000) and future (2031-2060) climate (see supplementary section 3 for details and model equations, available at stacks.iop.org/ERL/8/035010/mmedia).

We focused on 68 thermoelectric power plants in Europe, situated in different European countries and characterized by different sources of fuel and cooling system types (figure 2). For each country we selected thermoelectric power plants with the largest installed capacity and which use river water for cooling. Other criteria for selection were the availability of detailed information of the location, efficiency, cooling system and fuel type, and water temperature limits at the power plant site. Impacts of climate change on daily useable capacity of thermoelectric power plants were assessed for present power plant settings (i.e. current source of fuel and cooling system types), which is denoted henceforth as the 'baseline setting' (figure 2). In addition, we also quantified impacts of climate change on useable power capacities considering adaptation in the thermoelectric power sector with regard to replacement of cooling system type and changes in source of fuel. Two additional cases of adaptation were considered; (i) replacement of all once-through by recirculation (tower) cooling systems (denoted henceforth as 'adapt cooling'); and (ii) replacement of all once-through by recirculation cooling systems and replacement of all coal-, 
lignite- and oil-fuelled power plants by gas-fired power plants (denoted henceforth as 'adapt cooling + fuel'). Using the relative change in thermoelectric power plant capacities for the different power plant sites in each country we quantified for each country the average impacts of climate change on thermoelectric power under 'baseline setting', 'adapt cooling' and 'adapt cooling + fuel'.

Based on projected changes in thermoelectric and hydropower generating capacity under climate change, we calculated changes in wholesale electricity prices, production and electricity producer surplus. We used scenarios of future installed power plant capacities, electricity exchange capacities, cost figures and electricity demand based on the European Network of Transmission System Operators for Electricity (ENTSO-E 2010, 2011, 2012). Our calculations are based on the assumption that at each point in time electricity supply has to meet electricity demand. In addition, we assumed that existing power plants are used in order of their short-term marginal cost ${ }^{6}$. Country specific electricity supply curves were identified taking the cost for electricity imports into account. The wholesale price corresponds to the price where electricity supply meets demand, and the price at the wholesale market equals the production cost of the most expensive power plant in operation. We assumed a price elasticity of 0 for the demand for electricity, because changes in spot market prices have overall small impacts on end-user prices and demands. Equations $(1 a)-(1 c)$ show the optimization approach (objective function) of our model. Equation $(1 b)$ reflects that electricity supply has to meet electricity demand, whereas electricity can be supplied either by using domestic power plants or by importing electricity from a foreign country. Equation (1c) describes the grid capacities, which could be used to export electricity from country $n$ to country $m$.

$$
\begin{gathered}
\min Z_{t}=\sum_{n} \sum_{i} c_{i} \cdot s_{i, n, t} \cdot X_{i, n}+\sum_{n} \sum_{m} c_{l} \cdot \operatorname{imp}_{n, m, t}(1 a) \\
\sum_{t} s_{i, n, t} \cdot X_{i, n}+\sum_{m} \operatorname{imp}_{n, m, t} \geq d_{n, t} \quad \forall n \quad(1 b) \\
\operatorname{imp}_{n, m, t} \leq \mathrm{NTC}_{n, m} \quad \forall(n, m)
\end{gathered}
$$

where: $n, m=$ index for the country; $i=$ index for power plant type; $t=$ index for time $(-) ; c_{i}=$ operating costs of power plants of type $i\left(€ \mathrm{MWh}^{-1}\right) ; s_{i, n, t}=$ average utilization of power plants of type $i$ in country $n$, whereas $0 \leq s_{i, n} \leq$ $1(-) ; X_{i, n}=$ installed useable capacity of power plants of type $i$ in country $n$ (MW); $c_{l}=$ costs for transferring electricity from one country to another one $\left(€ \mathrm{MWh}^{-1}\right)$; $\mathrm{imp}_{n, m, t}=$ net-imports of electricity of country $n$ from country $m\left(€ \mathrm{MWh}^{-1}\right) ; d_{n, t}=$ electricity demand in country $n$ at time $t ; \mathrm{NTC}_{n, m}=$ net transfer capacities.

The cost optimization approach used in our dispatch model is implemented in GAMS (general algebraic modelling system) with an hourly time resolution. Prevailing constraints on net transfer capacities $\left(\mathrm{NTC}_{n, m}\right)$ and electricity demand $\left(d_{n, t}\right)$ are taken into account by using data of ENTSO-E

\footnotetext{
6 Short-term marginal cost comprises operation and maintenance cost as well
} as fuel cost, ignoring capital costs.
(2011, 2012). The demand ('load') figures of ENTSO-E include electricity demand of private households, industry and other sectors, and transmission losses. In addition, cost figures were used for international trade of electricity reflecting transmissions losses. The model uses data with power plant stock projections for 2030 of EURELECTRIC (2010). Taking the vintage structure of power plants into account the power plants are grouped in 36 different categories. Information of EURELECTRIC was used to draw inferences on power plant efficiencies and calculate power plant specific production cost by taking expected changes in fuel prices into account (EURELECTRIC 2010, IEA 2011a, 2011b). For siting of new power plants, we assumed that companies tend to prefer using existing power plants sites due to advantages regarding the approval procedure for new power plants and infrastructure aspects (e.g. vicinity to consumers, coal mines or gas pipelines, grid connection). Uncertainties regarding electricity demand and power plant availabilities were included by assuming that $5-10 \%$ of the generating capacity on country level will be available as spare capacity. Therefore, the available capacity at each point in time will not be used completely, and the mix used for supplying electricity can vary significantly between time slices (e.g. taking into account variations in wind and solar photovoltaics (PV) production).

Our analyses focused on 29 European countries which dominate electricity supply in the Europe. The share of various electricity production techniques for different European countries for the baseline situation is presented in figure $\mathrm{S} 2$ of the supplementary information (available at stacks.iop.org/ERL/8/035010/mmedia). The impacts of changes in power plant availability on overall profits were assessed by using a producer surplus approach. Electricity producer surplus reflects the difference between revenues suppliers of electricity obtained from selling electricity and the cost of supplying this electricity. Producer surplus depends not only on the level of the wholesale prices and the production volume but also on the slope of the cost curve (see supplementary section 4, available at stacks.iop.org/ERL/8/ 035010/mmedia and Rübbelke and Vögele (2013) for details).

\section{Results}

\subsection{Changes in river flow and water temperatures under climate change}

Spatial patterns of changes in mean river flow in Europe under future (2031-2060) relative to reference (1971-2000) climate show a strong division between the northern and southern part (figure 3(a)). An increase in mean annual river flow for northern Europe is projected with an average of 3-5\% (north of $52^{\circ} \mathrm{N}$ ), and an average decline for southern Europe of $13-15 \%$ (south of $52^{\circ} \mathrm{N}$ ) for the SRES B1-A2 scenario. Low flow values (10-percentile daily river flow) are projected to decline for almost whole of Europe except for Scandinavia (figure 3(b)). Strongest declines in mean and low flow are mainly projected for southern and south-eastern European countries (Portugal, Spain, Italy, Macedonia, Bulgaria and Greece) with declines of more than $20 \%$. 


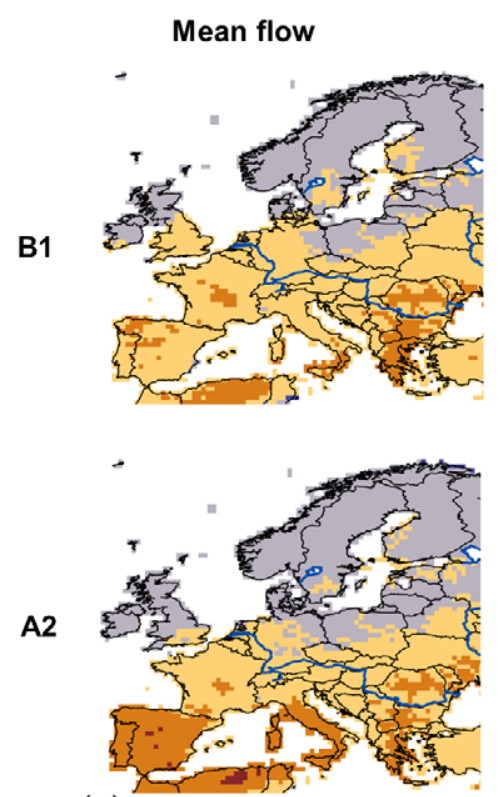

(a)

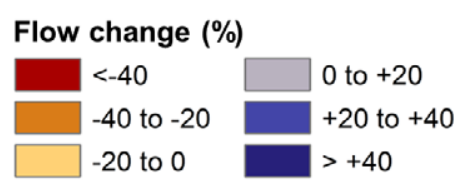

(b)
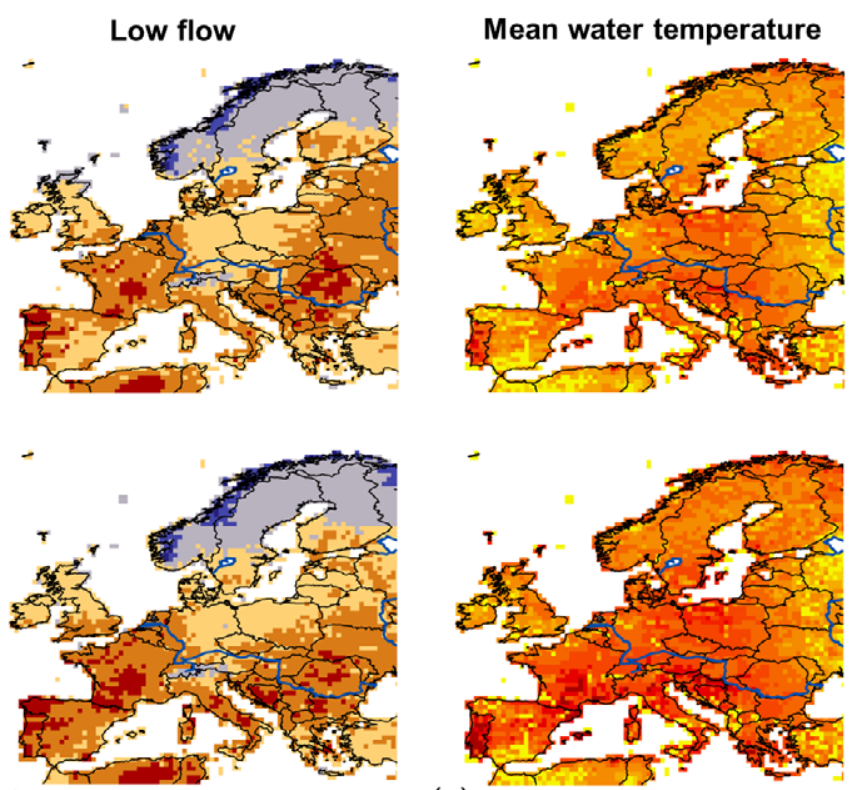

(c)

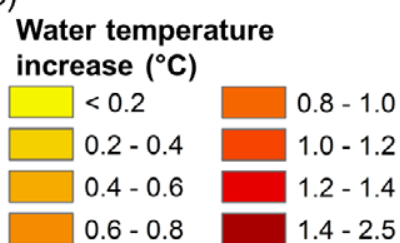

Figure 3. Climate change impacts on low river flows and water temperatures in Europe. Projected changes in mean flow (a) and low flows (10th percentile of daily distribution of river flow); (b) and mean water temperatures (c) for the 2031-2060 relative to 1971-2000. Changes are presented using the GCM ensemble mean changes for both the SRES A2 and B1 scenario relative to the reference period.

Increases in mean water temperature are largest $\left(>1^{\circ} \mathrm{C}\right)$ in central Europe (e.g. Switzerland, Austria, Slovenia, Hungary, Slovakia) and south-eastern parts (e.g. Romania, Bulgaria, Croatia, Serbia) (figure 3(c)). The average increase in mean annual water temperatures for the whole European region is $0.6-0.8^{\circ} \mathrm{C}$ (SRES B1-A2 for 2031-2060). Overall, larger increases in the high (95th percentile) water temperature range are projected (average of $0.9-1.1^{\circ} \mathrm{C}$ ). A combination of strong increases in water temperature and declines in low river flow is generally most critical for cooling water use. These conditions are mainly projected for southern, central and south-eastern Europe.

\subsection{Impacts on hydropower and thermoelectric power generating capacity}

Relative change in mean gross hydropower potential largely depicts the projected changes in mean annual river flow. A substantial $(>8 \%)$ increase in the potential to generate hydropower is projected for northern countries (Norway, Sweden, and Finland) (figure 4). Large (>15\%) declines in hydropower potential are projected for southern countries (Portugal, Spain, France) and southeast Europe (Balkan countries like Greece, Bulgaria, Romania, Serbia, Macedonia). There is also a group of countries at mid-northern latitude $\left(50-60^{\circ} \mathrm{N}\right)$ where gross hydropower potential is expected to show moderate changes under future climate (e.g. Latvia, Lithuania, UK and Ireland). In total, the gross hydropower potential of Europe is estimated to decrease on average by 4-5\% for the period 2031-2060 (SRES B1-A2) relative to 1971-2000.

Impacts of climate change on thermoelectric power generating capacity were assessed for the present power plant setting ('baseline setting') (figure 5(a)), for a scenario of replacement of all once-through by tower cooling systems ('adapt cooling') (figure 5(b)) and replacement of both cooling system and source of fuel ('adapt cooling + fuel') (figure 5(c)). The largest declines in mean useable capacity under 'baseline setting' are estimated for countries in southern and south-eastern Europe. The estimated reduction in summer mean useable capacity is $16-20 \%$ for Bulgaria and $15-21 \%$ for Spain (SRES B1-A2 for 2031-2060 relative to 1971-2000). Substantial reductions $(>5 \%)$ in summer mean thermoelectric power capacities are also expected for central European countries (Germany, Poland, Hungary, Ukraine, France, Belgium), where overall high increases in water temperatures combined with strong declines in low summer flow are projected. Replacement of cooling systems and changes in the sources of fuel lead to an overall reduction in the vulnerability of thermoelectric power plants to climate change. For example for power plants in Spain, a replacement of once-through by tower cooling systems ('adapt cooling') decreases the adverse impacts on summer mean useable capacity (reduction of 7-9\% for 'adapt cooling' compared to $15-21 \%$ for 'baseline setting' for SRES B1-A2 for 2031-2060). In addition, a replacement 


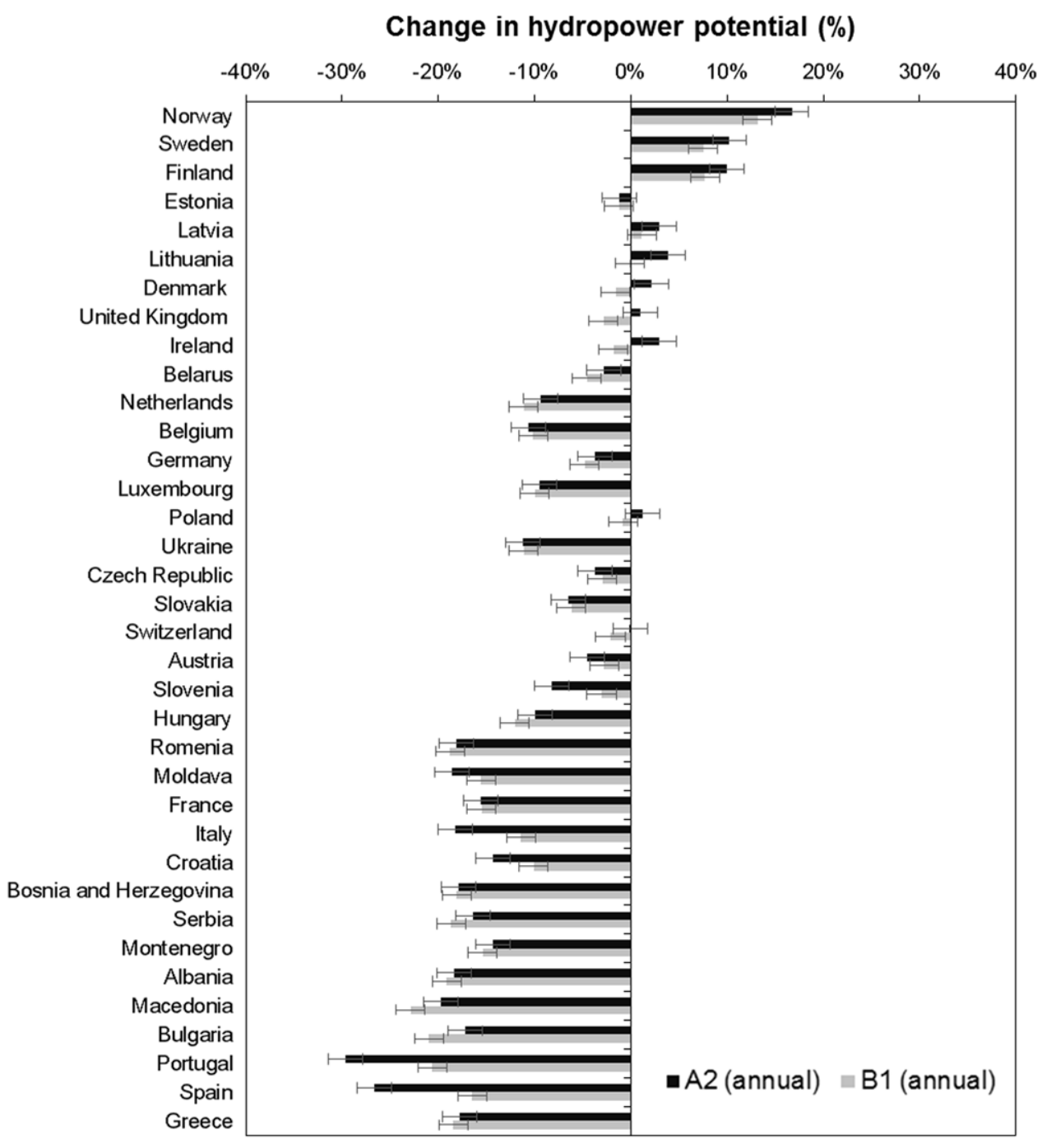

Figure 4. Country based statistics of relative (\%) changes in mean annual gross hydropower production potential under future climate (2031-2060) relative to current climate (1971-2000). Standard bars represent one standard error.

of fossil-fuelled power plants by new gas-fired power plants ('adapt cooling + fuel') further lowers reductions in summer mean useable capacity to $5-7 \%$, although impacts are still non-negligible for most countries in southern and central Europe. For Belgium, Czech Republic and Ukraine we found very limited impacts of replacements of cooling systems and sources of fuel, because most power plants in these countries are nuclear or gas-fired power plants that already used recirculation cooling systems under 'baseline setting'.

\subsection{Impacts on wholesale prices and distributional consequences}

Our calculations for the electricity system in Europe show that overall higher wholesale prices are expected for most countries (figure 6(a)), because the limitations in water availability and exceeded water temperature limits mainly affect power plants with low production cost (e.g. hydroelectric and nuclear power plants). Strongest increases in mean annual wholesale prices are projected for Slovenia (12-15\%), Bulgaria (21-23\%) and Romania (31-32\% for 2031-2060 relative to 1971-2000 for 'baseline setting'). Sweden and Norway are exceptions, because mean water availability is projected to increase in these countries, and consequently, more electricity will be produced there by using 'low-cost' hydroelectric power plants, putting costlier power plants out of operation. Wholesale prices during summer period are, however, expected to increase for Sweden (with 12\%). For most countries, the increases in wholesale electricity prices are higher for summer period than on mean annual basis, because restrictions in cooling water use for thermoelectric power and reductions in water availability for hydropower potential are highest during this season. Strongest increases in wholesale prices during summer are projected for Slovakia (14-19\%), France (14-17\%), Austria (22-25\%), Slovenia (25-33\%), Romania (55-60\%), and Bulgaria (44-45\% for SRES B1-A2 for 2031-2060 relative to 1971-2000).

Overall, the differences between the scenarios (i.e. B1 and A2 emission scenarios, and 'baseline settings' and 'adapt 
Change in thermoelectric power potential (\%)

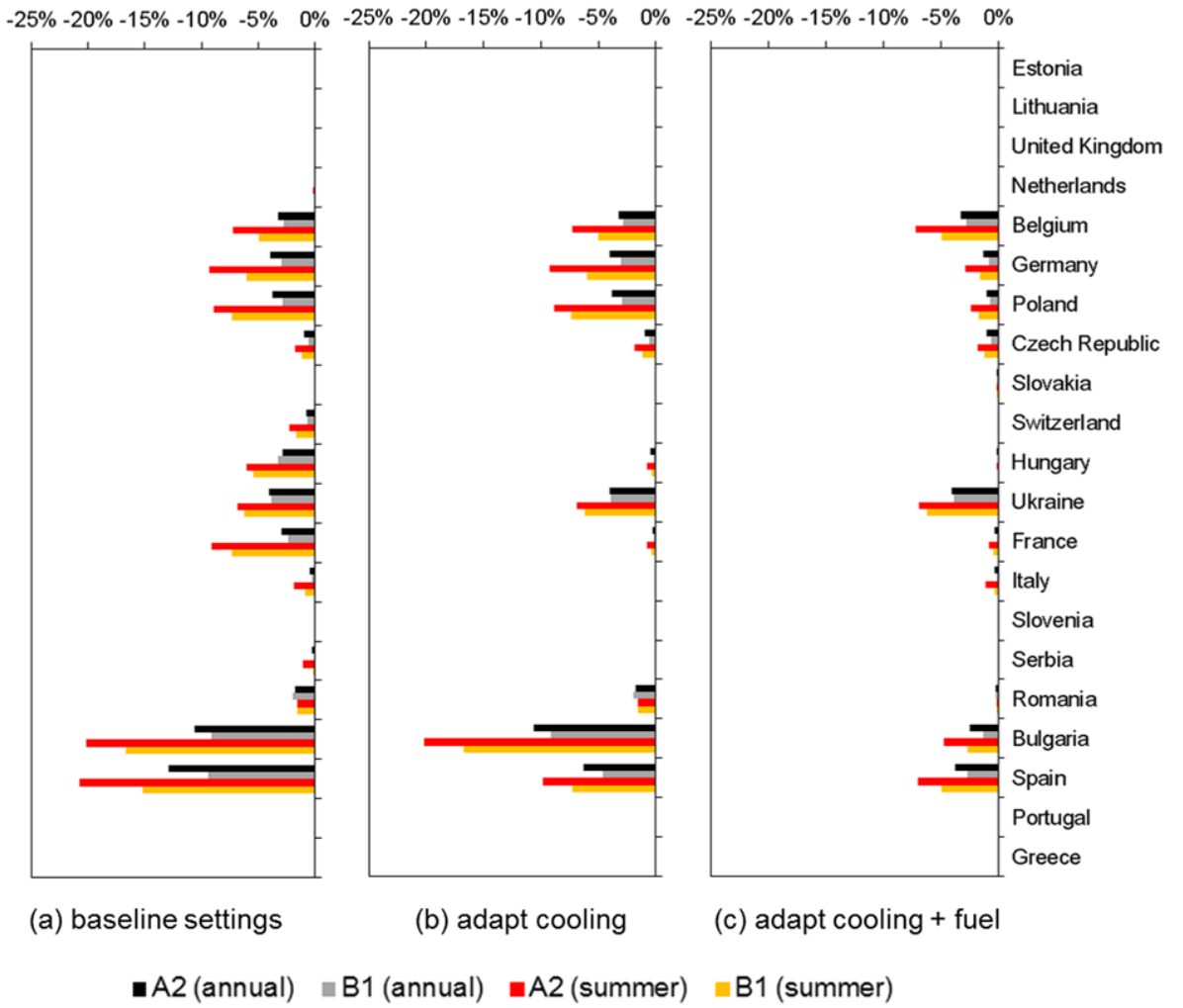

Figure 5. Country based statistics of relative (\%) changes in thermoelectric power production under future climate (2031-2060) relative to reference climate (1971-2000). Changes are presented on a mean annual basis and for summer period for present power plant setting ('baseline setting') (a), for a scenario of replacement of all once-through by tower cooling systems ('adapt cooling') (b) and replacement of both cooling system and source of fuel ('adapt cooling + fuel') (c).

cooling') are small (see figure 7 for selection of countries). The replacement of coal-fuelled power plants by gas-fuelled power plants is expected to result in high increases in wholesale prices, because the fuel cost of gas-fired power plants are significantly higher than of coal-fired power plants.

The changes in power plant availability and wholesale prices will also affect electricity import and export balances between countries. For instance, countries like Norway will export more electricity, while countries which have no or only expensive excess capacities (e.g. Albania) will import more electricity. Overall, electricity production will be extended in countries like Serbia (mean annual increase of $+5 \%$ ), Macedonia $(+10 \%)$ and Norway $(+4 \%)$, while considerable declines in electricity production (up to $15 \%$ ) are projected for other countries (e.g. Albania, Romania, Montenegro, Sweden) (figure 6(b)).

To assess the overall economic effect for producers, besides changes in production and wholesale prices, changes in the slope of the country specific cost curves were taken into account (Rübbelke and Vögele 2013). Producer surplus will increase considerably in France, Slovenia, Macedonia, Bulgaria and Romania, where increases are more than $10 \%$ on mean annual basis and more than $30 \%$ for summer period. Strong declines in mean annual producer surplus are expected for Norway and Sweden, which are mainly caused by decreasing wholesale prices of electricity (figure 6(c)).

\section{Discussion and conclusions}

This study shows that the combination of increased water temperatures and reduced summer river flow under climate change is likely to affect both hydropower and thermoelectric power generating capacity in Europe, with distinct impacts on electricity prices. An overall increase in mean hydropower generating potential is expected for northern European countries, but strong declines $(>15 \%)$ are expected in particular for the southern and south-eastern parts. For whole of Europe, gross hydropower potential is expected to decrease by $4-5 \%$ for the period 2031-2060 (SRES B1-A2) relative to $1971-2000$, which is in line with the $6-12 \%$ reduction in gross hydropower potential under climate change estimated by Lehner et al (2005) for the period around 2070.

Useable capacity of thermoelectric power is expected to be most strongly impacted in countries in the central, southern and south-eastern part of Europe, where strong declines in low summer river flow are projected in combination with large increases in water temperature. This is expected to increase environmental restrictions on cooling water uses, and can result in substantial reductions in power plant capacities during summer (up to 16-20\% for Bulgaria and 15-21\% for Spain for SRES B1-A2 for 2031-2060). Replacement in cooling systems and changes in sources of fuel (increased efficiency) reduce water demand of thermoelectric power 


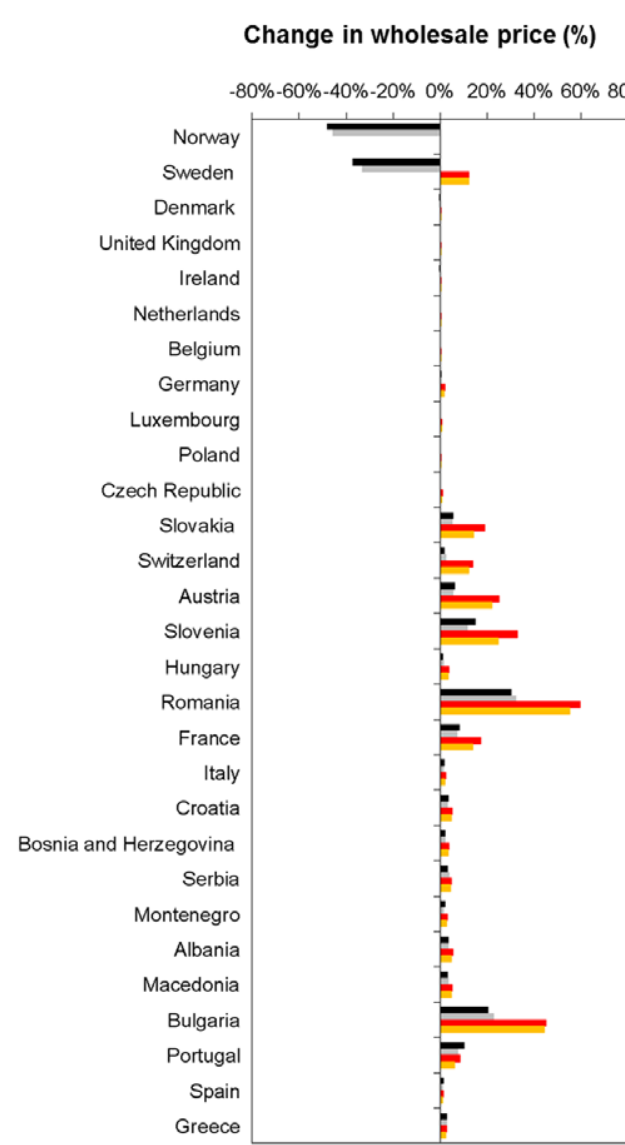

(a)

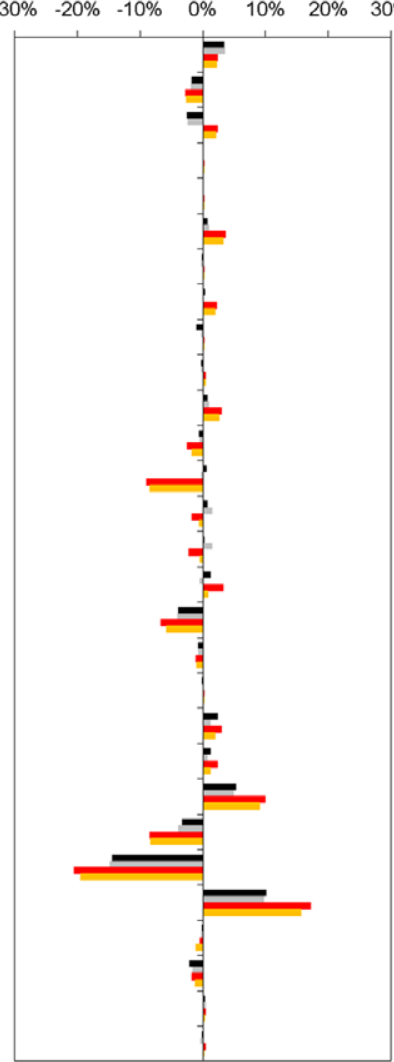

(b)

- A2 (annual)

॥1 (annual)

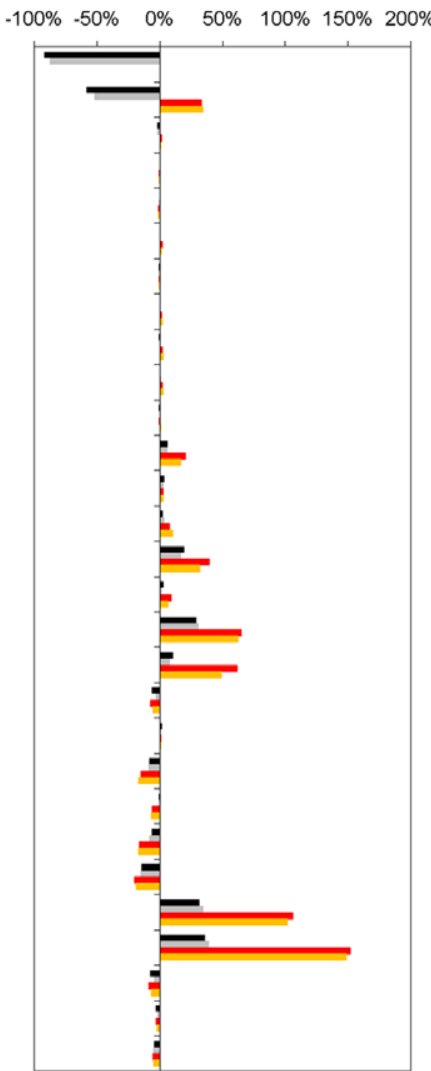

(c)

Figure 6. Impacts of changes in hydropower and thermoelectric power useable capacity on wholesale prices (a) production (b) and producer surplus (c) on annual mean basis and for summer period.

plants for cooling, and therefore decrease the vulnerability to climate change and aggravated cooling water shortage. However, estimated reductions in power plant useable capacities for power plants with recirculation (tower) cooling systems were smaller but still non-negligible, especially for countries in southern, central and south-eastern Europe.

The cost-optimal use of power plants was calculated on a country level. In our approach we assumed that a liberalized competitive electricity market prevails, but it should be noted that some electricity markets in European countries are still highly regulated and marginal cost pricing is only partly observed. In addition, it should be stressed that uncertainty prevails concerning relative pricing depending on prices of fossil fuels and environmental regulations in the future.

Overall, higher wholesale prices are projected for most European countries, as limitations in water availability mainly affect power plants with low production costs there. Exceptions are Sweden and Norway where water availability for hydropower generation will increase. The impacts of changes in power plant availabilities on national electricity supply systems also depend on the future structure of the power plant stocks. As long as 'inexpensive' excess capacities are available, decreases in power plant availabilities will be bearable, but significant changes in wholesale prices are projected in case no (or only expensive) excess capacities can be used. Although total welfare of market actors declines, some individual market actors might benefit from the impacts of more warm, dry summers on electricity generation patterns (e.g. in France, Slovenia, Macedonia, Bulgaria and Romania). These beneficiaries are not on the consumer side, but on the supply side.

Overall, more electricity will be traded with changes in power plant availabilities in Europe under future climate and changes in power plant stock. Autonomous adaptation via the European electricity market provides opportunities to partly compensate for the loss of power generating capacity in one subsector or plant location by an increase in power generation in another sector or location (Rübbelke and Vögele 2013). However, considering the high shares of hydropower, coal-fuelled and nuclear-fuelled power plants in most European countries, the vulnerability to declines in summer river flow and increased water temperatures can be high. Planned adaptation strategies are therefore highly recommended, especially in the southern, central and south-eastern parts of Europe, where overall largest impacts on thermoelectric and hydropower generating capacity are 


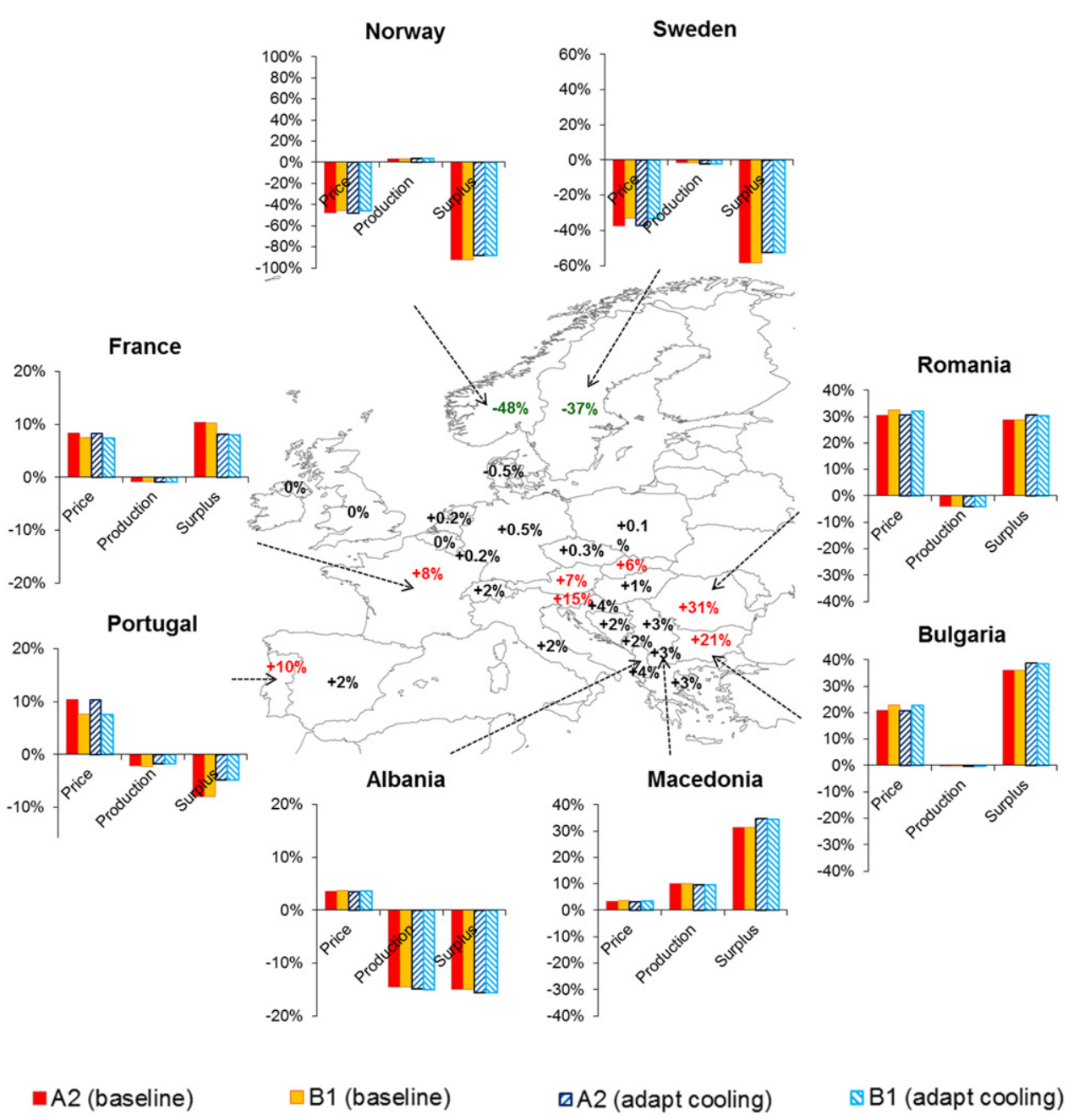

Figure 7. Impacts of changes in hydropower and thermoelectric power useable capacity on mean annual wholesale prices, production, and producer surplus for a selection of countries with substantial economic impacts ( $>10 \%$ change). Impacts are presented for both the SRES A2 and B1 emission scenarios and for both the 'baseline setting' and 'adapt cooling'. Values in the maps show the change in mean annual wholesale electricity prices for SRES A2 with 'baseline setting' of power plants.

projected under climate change. Considering the high investments costs (EPRI 2011), retrofitting or replacement of power plants might not be beneficial from the perspective of individual power plant operators, although the social benefits of adaptation could be substantial.

An increased diversification in the electricity sector, with a larger contribution of renewable energy resources that are independent from water availability and water temperature (e.g. solar PV, wind power), might reduce the vulnerability of the electricity sector to climate change, although wind power can also be negatively affected by climate change (Breslow and Sailor 2002). Overall, solar PV and wind power have low production costs, but require considerable backup capacities to compensate for fluctuations in the electricity generation potential. In addition, grid extensions might be required for ensuring electricity supply if the shares of these electricity production technologies increase significantly. Considering the long design life of power plant infrastructure, short-term adaptation strategies are highly recommended to prevent misallocation of resources and to assure future energy security.

\section{Acknowledgment}

This study was financially supported by the European Commission through the FP7 ECLISE project to Wageningen University.

\section{References}

Boogert A and Dupont D 2005 The nature of supply side effects on electricity prices: the impact of water temperature Econ. Lett. 88 121-5

Breslow P B and Sailor D J 2002 Vulnerability of wind power resources to climate change in the continental United States Renew. Energy 27 585-98

Davies E G R, Kyle P and Edmonds J A 2013 An integrated assessment of global and regional water demands for electricity generation to 2095 Adv. Water Resour. 52 296-313

EEA 2012 Climate Change, Impacts and Vulnerability in Europe 2012: An Indicator-Based Report (Copenhagen: European Environment Agency)

ENTSO-E 2010 Data Portal: Country Data Packages (www.entsoe. eu/data/data-portal/country-packages/) 
ENTSO-E 2011 NTC Values (www.entsoe.eu/resources/ntc-values/ ntc-matrix)

ENTSO-E 2012 Ten-Year Network Development Plan 2012 Brussels-Project for Consultation (available at www.entsoe.eu/)

EPRI 2011 National cost estimate for retrofit of US power plants with closed-cycle cooling Technical Brief-Clean Water Act Fish Protection Issues (Palo Alto, CA: Electric Power Research Institute) pp 1-2 (available at www.epri.com/)

EUREAU 2009 EUREAU Statistics Overview on Water and Wastewater in Europe 2008 (Brussels: European Federation of National Associations of Water and Wastewater Services)

EURELECTRIC 2010 Power Statistics (Brussels: Union of the Electricity Industry-EURELECTRIC)

Flörke M, Barlund I and Kynast E 2012 Will climate change affect the electricity production sector? a European study J. Water Clim. Change 3 44-54

Flörke M, Teichert E and Bärlund I 2011 Future changes of freshwater needs in European power plants Manag. Environ. Qual.: An Int. J. 22 89-104

Förster H and Lilliestam J 2010 Modeling thermoelectric power generation in view of climate change Reg. Environ. Change 10 327-38

GEA 2012 Global Energy Assessment-Toward a Sustainable Future (Cambridge: Cambridge University Press) (Laxenburg: International Institute for Applied Systems Analysis)

Hagemann S, Chen C, Haerter J O, Heinke J, Gerten D and Piani C 2011 Impact of a statistical bias correction on the projected hydrological changes obtained from three GCMs and two hydrology models J. Hydrometeorol. 12 556-78

Hoffmann B, Häfele S and Karl U 2013 Analysis of performance losses of thermal power plants in Germany-a system dynamics model approach using data from regional climate modelling Energy 49 193-203

IEA 2011a World Energy Outlook 2011 (Paris: OECD/IEA)

IEA 2011b World Energy Outlook-Investment Costs (www. worldenergyoutlook.org/investments.asp)

Koch H and Vögele S 2009 Dynamic modelling of water demand, water availability and adaptation strategies for power plants to global change Ecol. Econ. 68 2031-9

Kopytko N and Perkins J 2011 Climate change, nuclear power, and the adaptation-mitigation dilemma Energy Policy 39 318-33

Kuusisto E 2004 Droughts in Finland-past, present and future Hydrol. Days 2004 143-7

Kyle P, Davies E G R, Dooley J J, Smith S J, Clarke L E, Edmonds J A and Hejazi M 2013 Influence of climate change mitigation technology on global demands of water for electricity generation Int. J. Greenhouse Gas Control 13 112-23
Lehner B, Czisch G and Vassolo S 2005 The impact of global change on the hydropower potential of Europe: a model-based analysis Energy Policy 33 839-55

Liang X, Lettenmaier D P, Wood E F and Burges S J 1994 A simple hydrologically based model of land-surface water and energy fluxes for general-circulation models J. Geophys. Res.-Atmos. 99 14415-28

Linnerud K, Mideksa T K and Eskeland G S 2011 The impact of climate change on nuclear power supply Energy J. 32 149-68

McDermott G R and Nilsen ØA 2011 Electricity prices, river temperatures and cooling water scarcity Discussion Paper Series in Economics 18/2011 (Bergen: Department of Economics, Norwegian School of Economics)

Mideksa T K and Kallbekken S 2010 The impact of climate change on the electricity market: a review Energy Policy 38 3579-85

Nakicenovic N et al 2000 Emissions Scenarios. A Special Report of Working Group III of the Intergovernmental Panel on Climate Change (Cambridge: Cambridge University Press)

Punys P, Tirunas D, Bagdziunaite-Litvinaitiene L and Pelikan B 2008 The impact of climate change on Kaunas hydropower plant power production 7th Int. Conf. 'Environmental Engineering' pp 674-9

Rübbelke D and Vögele S 2011 Impacts of climate change on European critical infrastructures: the case of the power sector Environ. Sci. Policy 14 53-63

Rübbelke D and Vögele S 2013 Short-term distributional consequences of climate change impacts on the power sector: who gains and who loses? Clim. Change 116 191-206

Schmidt-Thomé P and Kallio H 2006 Natural and technological hazard maps of Europe Natural and Technological Hazards and Risks Affecting the Spatial Development of European Regions (Geological Survey of Finland, Special Paper 42) pp 17-63

Van Vliet M T H, Franssen W H P, Yearsley J R, Ludwig F, Haddeland I, Lettenmaier D P and Kabat P 2013 Global river discharge and water temperature under climate change Glob. Environ. Change 23 450-64

Van Vliet M T H, Yearsley J R, Franssen W H P, Ludwig F, Haddeland I, Lettenmaier D P and Kabat P 2012a Coupled daily streamflow and water temperature modelling in large river basins Hydrol. Earth Syst. Sci. 16 4303-21

Van Vliet M T H, Yearsley J R, Ludwig F, Vögele S, Lettenmaier D P and Kabat P 2012b Vulnerability of US and European electricity supply to climate change Nature Clim. Change 2 676-81

Yearsley J R 2009 A semi-Lagrangian water temperature model for advection-dominated river systems Water Resources Res. $45 \mathrm{~W} 12405$

Yearsley J R 2012 A grid-based approach for simulating stream temperature Water Resources Res. 48 W03506 